\title{
La transgresión de la imprescriptibilidad en los delitos de corrupción
}

\author{
The transgression of imprescriptibility in crimes of corruption
}

A transgressão da imprescritibilidade em crimes de corrupção

Artículo recibido en enero 2021

Arbitraje en febrero 2021

Aceptación en marzo 2021

Publicación en abril 2021
Jimena Portugal Dorado

jimenadoradoportugal@gmail.com

https://orcid.org/ 0000-0002-7235-8947

Universidad Andina Simón Bolívar, Sucre, Bolivia
RESUMEN

\section{ABSTRACT}

\section{RESUMO}

La investigación tuvo por objetivo analizar la identificación de la naturaleza de la figura jurídica en los delitos de corrupción incorporada en la legislación boliviana. Con una metodología de tipo descriptivo- propositivo, un enfoque cualitativo, y diseño documental, además se utilizó los métodos analítico, deductivo e inductivo. La población y muestra estuvo conformada por tres expertos, los mismos que determinaron su posición profesional, desde la óptica doctrinaria, experticia y académica de la imprescriptibilidad de delitos de corrupción. Como técnicas e instrumentos, se utilizaron la entrevista y un cuestionario a los expertos entrevistados. Se obtuvo como resultado, la afectación en la seguridad jurídica. Concluyendo que con la propuesta se garantizará el principio de legalidad y el sometimiento de control internacional de cumplimiento de las obligaciones internacionales.

Palabras clave: Delitos; corrupción; legislación boliviana; ley 004, transgresión

The main objective of the investigation is to analyze the identification of the nature of the legal figure in corruption crimes incorporated in Bolivian legislation. With a descriptive-propositional methodology, a qualitative approach, and documentary design, the analytical, deductive and inductive methods were also used. The population and sample consisted of three experts, the same who determined their professional position, from the doctrinal, expert and academic point of view of the imprescriptibility of corruption crimes. As techniques and instruments, the interview and a questionnaire to the interviewed experts were used. As a result, the effect on legal security was obtained. Concluding, that the proposal will guarantee the principle of legality and the submission of international control of compliance with international obligation.

Key words: Crimes; corruption; Bolivian legislation; law 004, transgression

O objetivo principal da investigação é analisar por meio da identificação da natureza da figura jurídica dos crimes de corrupção incorporados na legislação boliviana. Com metodologia descritiva-proposicional, abordagem qualitativa, e desenho documental, também foram utilizados os métodos analítico, dedutivo e indutivo. A população e a amostra foram constituídas por três peritos, os mesmos que determinaram a sua posição profissional, do ponto de vista doutrinal, pericial e académico da imprescritibilidade dos crimes de corrupção. Como técnicas e instrumentos, utilizou-se a entrevista e um questionário aos especialistas entrevistados. Com isso, obteve-se o efeito na segurança jurídica. Concluindo, que a proposta garantirá o princípio da legalidade e a submissão do controle internacional do cumprimento das obrigações internacionais.

Palavras-chave: Crimes; corrupção; Legislação boliviana; lei 004, transgressão 
El ordenamiento jurídico boliviano ha incorporado la prescripción como una institución fundamental de su sistema penal, toda vez que las reglas específicas que determinan los plazos de prescripción varían entre un delito y otro, estando directamente vinculados al plazo de las penas privativas de libertad establecidas para sancionar los delitos.

A nivel internacional, la Convención de las Naciones Unidad contra la Delincuencia Organizada Transnacional (2000) señala que "cada Estado Parte establecerá, cuando proceda, con arreglo a su derecho interno, un plazo de prescripción prolongado dentro del cual pueda iniciarse el proceso por cualquiera de los delitos comprendidos en la presente Convención" (artículo 11, numeral 5). Tomándose en cuenta que esta Convención ha sido ratificada en los cuatro países de la región y consecuentemente es una norma internacional vigente.

Dado que el Estado quiere intensificar el problema de la persecución respecto al tema de corrupción, ha apostado por la imprescriptibilidad de estos delitos, lanzando un mensaje muy claro en ese sentido, analizando la supuesta eficacia de estas disposiciones a la luz de un conjunto de acciones y no solamente de una. Pero toda esa intensidad, que se pretende demostrar, también puede terminar generando una afectación a los derechos de los investigados. Puntualizando que la normativa de la Constitución Política autoriza la aplicación retroactiva de la ley penal para los casos de corrupción de funcionarios. En términos generales, Bolivia debe mantener el respeto al principio de legalidad como una pieza clave de la lucha contra la corrupción.

Cabe destacar que en la legislación de Bolivia no existe un derecho constitucional a la prescripción, sino más bien se hace prevalecer el derecho a los principios de legalidad, seguridad jurídica e igualdad. Así evitar que estos principios no sean lesionados por el mismo Estado en algún momento dentro de un proceso, haciéndose efectivo lo antes mencionado, en tanto los plazos establecidos en todo el esquema procedimental penal, desde la denuncia hasta su juzgamiento con la sentencia, sean razonables y se encuentren definidos y limitados por la Ley.

Es así que se fija de manera notable la necesidad de limitar al Estado sobre el derecho punitivo.

En ese sentido, ponderar los delitos de la administración pública con los delitos de lesa humanidad, al resolverlos como imprescriptibles, es un arma de doble filo, ya que si la necesidad social es alcanzar resultados rápidos, efectivos y eficaces, lo único que se está haciendo es consolidar procesos que van a durar 20 o 30 años y por lo tanto, si no es prescriptible un juicio de esa naturaleza, durará hasta el fallecimiento del imputado, es decir que se tiene dos tipos de causas: por un lado, están las que prescribieron hace bastante tiempo incluso antes de la aplicación de la Ley 004 por falta de impulso, y otro lado, están los delitos de corrupción cometidos dentro la vigencia de la Ley Marcelo Quiroga Santa Cruz. 
Lo antes mencionado es contradictorio a la incorporación del pacto de San José de Costa Rica en el ordenamiento jurídico de Bolivia, dado a que, es el acortamiento precisamente de un proceso que da celeridad al mismo para tener sentencias definitivas.

Si se toma en cuenta que la imprescriptibilidad tiene como finalidad evitar la impunidad en varios casos de corrupción descarada, solo en ese sentido, puede ser una medida muy positiva. Sin embargo, de cualquier manera, no se debe dejar de lado que el problema primordial no es que las causas prescriban a los 20 años, sino que al contrario lleguen a durar más de ese tiempo.

Por otro lado, la imprescriptibilidad, contrario a lo señalado en la Ley 004, podría propiciar procesos de investigación muy amplios, provocando de esa forma que la calidad de las pruebas se pueda afectar. En este sentido, la investigación tiene por objetivo principal, analizar, a través de la identificación de la naturaleza de la figura jurídica en los delitos de corrupción incorporada en la legislación boliviana.

El aporte de la investigación se sustenta en la necesidad del estudio sobre la cuestionable calificación de los delitos de corrupción como imprescriptibles, ya que, incumple el reconocimiento de la jurisdicción de los Organismos Internacionales, al ser el Estado Boliviano miembro activo de éstos, y habiéndose incluido cláusulas abiertas sobre derechos humanos en la Constitución y la aplicación de los tratados y convenios internacionales en el orden interno, constituye un despropósito pretender que la normativa vigente se aparte y confronte la armonía legal, tomando en cuenta asimismo que la aplicación tardía de la pena carece de eficacia o ejemplaridad con el transcurso del tiempo debilitando la finalidad de la misma norma.

\section{Marco Teórico}

\section{Jurídico-penal de corrupción}

Según el Instituto de Defensa Legal (2012), la corrupción se entiende como un poder oculto que define las relaciones reciprocas entre la economía y la política. En efecto, la corrupción no se reduce a una transferencia de recursos del ámbito público al privado o al usufructo de la autoridad pública para obtener ventajas personales, sino que constituye en términos criminológicos más amplios, una interacción que se aparta de las expectativas normativas.

Además, el Instituto de Defensa Legal (2012) conceptualiza la corrupción como:

La conducta de quien ejerce una cierta función social que implica determinadas obligaciones activas o pasivas destinadas a satisfacer ciertos fines, para cuya consecución fue designado en esa función, y no cumple con aquellas obligaciones o no las cumple deforma de satisfacer esos fines, de modo de obtener un cierto beneficio para el o un tercero, así como también la conducta del tercero que lo induce o se beneficia con tal incumplimiento. 


\section{Corrupción y Enriquecimiento Ilícito Según la Ley Marcelo Quiroga Santa Cruz}

En la Ley 004 (2010) de Lucha contra la Corrupción, Enriquecimiento Ilícito e Investigación de Fortunas en su Capítulo I. Disposiciones Generales, define corrupción en su artículo 1:

Es el requerimiento o la aceptación, el ofrecimiento u otorgamiento directo o indirecto, de un servidor público, de una persona natural o jurídica, nacional o extranjera, de cualquier objeto de valor pecuniario u otros beneficios como dádivas, favores, promesas o ventajas para sí mismo o para otra persona o entidad, a cambio de la acción u omisión de cualquier acto que afecte a los intereses del Estado.

Según la Ley N. ${ }^{\circ} 004$ (2010), en su artículo 27 de Lucha contra la Corrupción, Enriquecimiento Ilícito e Investigación de Fortunas. Capítulo III. Delitos de Corrupción, conceptualiza el "enriquecimiento ilícito" como:

La servidora pública o servidor público, que hubiere incrementado desproporcionadamente su patrimonio respecto de sus ingresos legítimos y que no pueda ser justificado, será sancionado con privación de libertad de cinco a diez años, inhabilitación para el ejercicio de la función pública y/o cargos electos, multa de doscientos hasta quinientos días y el decomiso de los bienes obtenidos ilegalmente.

\section{Naturaleza y Fundamento de la Prescripción}

Tomándose en cuenta que la prescripción se sostiene sobre la base del principio "pro homine", cuyo fin es restringir el "ius puniendi" del Estado, es decir, el Estado renuncia a su "iuspuniendi" por el transcurso del tiempo, por lo que consecuentemente genera el declive de derechos $u$ obligaciones por la inactividad del sujeto legitimado para ejercerlo, se ha podido extraer la doctrina aplicada en la legislación boliviana, la base de los cimientos fundamentales de la prescripción conforme se tiene del entendimiento jurisprudencial contenido en la SC 0023/2007 de 16 de enero que precisó en ese ámbito, la citada Sentencia Constitucional estableció respecto a la prescripción lo siguiente:

De acuerdo a la doctrina, la prescripción se traduce en los efectos que produce el transcurso del tiempo sobre el ejercicio de una determinada facultad. Esta definición, aplicada al ámbito penal, significa la expresa renuncia por parte del Estado del derecho a juzgar debido al tiempo transcurrido.

Conforme a ello, es el propio Estado el que, a través de la norma penal (procesal o sustantiva, según las legislaciones), establece los límites de tiempo en que puede ejercer la persecución penal. La actividad represiva del Estado no puede ser ejercida de manera indefinida, ya que al hacerlo se quebrantaría el equilibrio que debe existir entre la función de defensa de la sociedad y la protección de derechos y garantías individuales. 
Tradicionalmente se ha fundamentado la prescripción en diferentes razones, unas de tipo subjetivo, vinculadas a los cambios que el tiempo opera en la personalidad del delincuente, que determinan la desaparición de su peligrosidad para la sociedad; otras consideradas objetivas y de utilidad social, que señalan que con el transcurso del tiempo desaparece la alarma social y no existe necesidad de prevención general; aquellas de orden procesal que sostienen que existen dificultades en la recolección de elementos probatorios para determinar la culpabilidad o inocencia del presunto autor. También se han aducido razones de política criminal, en sentido que el castigo impuesto mucho tiempo después de la comisión del hecho no alcanza los fines de la pena (prevención especial y prevención general, positiva y negativa), careciendo, en consecuencia, su imposición de razón de ser; así como razones jurídicas, que inciden en la necesidad de eliminar la incertidumbre en las relaciones jurídicas y la desaparición de la intranquilidad causada por el delito" (Tribunal Constitucional Plurinacional, 2007).

Ahorabien, conforme lo mencionado "utsupra”, lo que se pretende con la prescripción es optimizar la eficiencia y la celeridad con que se llevan a cabo las investigaciones, lo cual forzosamente obliga a los operadores de justicia a actuar diligentemente, esto para poder determinar con la celeridad debida, la responsabilidad e imponer las sanciones correspondientes, evitando con ello posibles impunidades.

\section{Prescripción}

Según Castro (2003) establece que la prescripción es la extinción que se produce, por el solo transcurso del tiempo, del derecho a perseguir o castigar a una persona, cuando desde la comisión del hecho punible hasta el momento en que se trata de enjuiciarlo o después de haberse dictado sentencia firme, se ha cumplido el lapso marcado por la Ley. Es decir, que la prescripción es un medio de liberarse de las consecuencias penales y civiles de una infracción penal o una condena penal por el efecto del tiempo y en las condiciones exigidas por la Ley.

En otro orden de ideas, Freire (1998) señala que la prescripción de la acción penal tiene por objeto poner fin a la potestad represiva antes que la misma se haya manifestado en una sentencia condenatoria firme. Esto ocurre ya sea porque iniciada la persecución se omitió proseguirla con la continuidad debida y dentro de un plazo legal.

Por su parte, el profesor Villanueva (2009) indica que la base de la prescripción reside en la seguridad jurídica, pues el transcurso del tiempo provoca inexorablemente cambios en las relaciones o situaciones jurídicas.

\section{Imprescriptibilidad}

De acuerdo con la realidad boliviana, no todos los delitos prescriben, el Código Penal establece puntualmente cuales son los delitos prescriptibles, y por otro lado establece explícitamente cuales son aquellos delitos que se consideran imprescriptibles, tal es el caso de los tipos penales 
en relación a los delitos de corrupción. De esta manera, por mucho tiempo que transcurra, ciertas acciones delictivas no pueden acogerse a la figura de la prescripción.

\section{Principio de imprescriptibilidad vs. Principio de legalidad}

Una de las principales críticas -aún vigentes- que se plantea para la aplicación del principio de imprescriptibilidad está referida a la colisión o vulneración de principios vigentes del derecho penal reconocidos por sendos tratados y convenciones internacionales, se refiere al principio de legalidad e irretroactividad de la ley penal. Es así que los principales detractores de la aplicación del principio de imprescriptibilidad han señalado:

- Si al tiempo de cometerse las conductas delictivas estas no estaban tipificadas como delitos de lesa humanidad, no se puede procesar, como tales, en base al ordenamiento legal vigente por cuanto se viola el principio de legalidad e irretroactividad de la ley penal y por ende tampoco es aplicable el principio de imprescriptibilidad.

- Cuando las conductas de violaciones a los derechos humanos, al momento de perpetrarse los hechos delictivos, no se encontraban tipificadas como delitos de lesa humanidad, en los ordenamientos internos, la aplicación del principio de imprescriptibilidad estaría colisionando con el principio de legalidad, puesto que este principio (imprescriptibilidad) se aplica -sólo- para conductas tipificadas en el derecho interno como delitos de lesa humanidad, tomándose en cuenta que los delitos de Corrupción no son considerados como tales.

Mientras que el principio de legalidad penal supone cuatro exigencias al tipo penal, como los son: a una lex praevia, scripta, stricta et cert., sin estos elementos a reflexionar ningún individuo puede ser sujeto a proceso legal alguno. De lo contrario se le estaría vulnerando un derecho fundamental garantía de un Estado de Derecho.

\section{Fundamentos legales}

La presente investigación se apoyó de las siguientes bases legales, como es la Constitución Política del Estado, en sus artículos14,115,119, y 180, donde se establecen que todo ser humano tiene personalidad y capacidad jurídica con arreglo a las leyes y goza de los derechos reconocidos por esta Constitución, sin distinción alguna. Además, el Estado garantiza el derecho al debido proceso, a la defensa y a una justica plural, pronta, oportuna, gratuita, transparente, entre otros.

La ley de 1970, en su artículo 133, donde se establece la duración máxima del proceso, el cual indica que todo proceso tendrá una duración máxima de tres años contados desde el primer acto del procedimiento, salvo el caso de rebeldía.

Adicional, se tomaron en cuenta para el estudio algunos tratados y convenios internacionales aplicables en el proceso penal en defensa del imputado; como los fueron: 
- Convención Americana sobre Derechos Humanos (CADH) (Pacto de San José).

- Corte Interamericana de Derechos Humanos.

- El Pacto Internacional de Derechos Civiles y Políticos.

- Declaración Universal de los Derechos Humanos.

- La Declaración Americana de Derechos Humanos.

\section{Derecho comparado}

Como consecuencia del progresivo crecimiento de los delitos de corrupción, varios países han tomado la decisión de reformular sus legislaciones y declarar como imprescriptibles algunos delitos de corrupción y contra la función pública. Para tales efectos, han tenido que reformar su marco jurídico incluso elevándolo a nivel constitucional; entre los cuales se mencionan: Ecuador, Bolivia y Venezuela. Por su parte Argentina y Perú están en vías de declararlo.

\section{Ecuador}

El artículo 233 de la Constitución de la República del Ecuador, 2008 indica:

Las servidoras o servidores públicos y los delegados o representantes a los cuerpos colegiados de las instituciones del Estado, estarán sujetos a las sanciones establecidas por delitos de peculado, cohecho, concusión y enriquecimiento ilícito. La acción para perseguirlos y las penas correspondientes serán imprescriptibles y, en estos casos, los juicios se iniciarán y continuarán incluso en ausencia de las personas acusadas. Estas normas también se aplicarán a quienes participen en estos delitos, aun cuando no tengan las calidades antes señaladas.

\section{Venezuela}

En la Constitución de la República Bolivariana de Venezuela en el artículo $N^{\circ} 271$ expresa: "No prescribirán las acciones judiciales dirigidas a sancionar los delitos contra los derechos humanos, o contra el patrimonio público o el tráfico de estupefacientes".

MÉTODO

La investigación se desarrolló con una metodología de tipo descriptivo-propositivo, bajo un enfoque cualitativo, y un diseño documental.

Los métodos utilizados fueron analítico, deductivo e inductivo.

Por otro lado, la población y muestra que se utilizó para la recolección de datos, estuvo conformada por tres expertos, los mismos que determinaron su posición profesional, desde la óptica doctrinaria, experticia y académica de la imprescriptibilidad de delitos de corrupción.

Como técnicas e instrumentos, se utilizaron la entrevistas y cuestionario a los expertos entrevistados. 
Tabla 1. Perfil de entrevista a expertos.

\section{IMPRESCRIPTIBILIDAD \\ DE DELITOS DE \\ CORRUPCIÓN PUBLICA}

Se desea conocer la opinión de expertos respecto de la imprescriptibilidad de delitos de corrupción pública

Se desea conocer si la imprescriptibilidad transgrede pactos y tratados internacionales

\section{PERFILES DE EXPERTOS}

Abogado, con competencias en derechos humanos, derecho penal, constitucional, administrativo; con experiencia en funciones relacionadas como operador de justicia, administrador de justicia,

contralor de justicia, ente legislativo, administración pública.

Abogado, con competencias en derecho internacional, derechos humanos, derecho penal, constitucional, administrativo; con experiencia en funciones relacionadas como operador de justicia, administrador de justicia, contralor de justicia, ente legislativo,

administración pública.

RESULTADOS

Posterior a la aplicación del instrumento, se obtuvieron los siguientes resultados.

Ítems 1. Los antecedentes de corrupción en Bolivia, se justifica la aplicación de la imprescriptibilidad de ese tipo de delitos, como medida de persecución penal en hechos de corrupción.

\section{Entrevistado 1}

Indicó que no, porque el Estado quien es el que ejercita el jus puniendi, quiere hacer pagar su lenidad y la falta de preparación por parte de los representantes estatales, (ministerio público, procuraduría, jueces), quienes quieren hacer pagar al ciudadano que se encuentra siendo sujeto a una investigación. Asimismo, existe un tema, a nivel universal, referentes a que, en los delitos de corrupción no existen antecedentes de imprescriptibilidad, ya que, los únicos reconocidos son los delitos de lesa humanidad y la corrupción no es un delito de lesa humanidad. Si bien la corrupción genera graves consecuencias, empero, el entrevistado 1, no estuvo de acuerdo a que sean imprescriptibles. Uno de los puntos que ha discutido el Estatuto de Roma para la imprescriptibilidad se refiere precisamente por la decadencia probatoria, es decir, tanto las pruebas a favor como en contra, no disponen en las partes por largos lapsos, ambos puntos no solo perjudica la defensa, si no la acusación, porque no cumple la exigencia del debido proceso sustantivo bajo su faceta de proporcionalidad, es decir no es proporcional que un ser humano este eternamente perseguido por el Estado a partir de la supuesta o no comisión de un delito de corrupción. El Estado debería ser ágil y competente y no hacerle pagar a las personas por su lenidad. Es un problema más de debido proceso sustantivo y su faceta de desproporcionalidad. 
De esta forma, el entrevistado 1, argumentó ausencia de antecedentes en delitos de corrupción con imprescriptibilidad y resaltó que, los únicos delitos imprescriptibles, son los delitos de lesa humanidad, delimitando desproporcionalidad. Asimismo, en el entendido de la decadencia probatoria en sentido de que no permanecen por largos lapsos de tiempo, hizo énfasis que, precisamente a no encontrar carga de prueba se genera una eterna investigación que hace una persecución eterna sin substanciación en el proceso y desproporcional.

En síntesis, se determinó con lo expresado por el entrevistado 1, que no se justifica pues la persecución es desproporcional y que no se tiene un debido proceso sustantivo.

\section{Entrevistado 2.}

Indicó que no se justifica la imprescriptibilidad en este tipo de delitos porque el poder coercitivo y sancionador del Estado debe tener un tiempo definido y no indefinido, por lo que afectaría la seguridad jurídica que debe seguir un Estado de derecho y la vulneración del debido proceso por lo cual, dejar esta cláusula abierta de la imprescriptibilidad de los delitos de corrupción, seria ampliar un poder coercitivo y sancionador penal por parte del Estado en contra de un ciudadano al ser perseguido por un periodo indefinido.

En este sentido, el entrevistado 2 señaló que el poder coercitivo y sancionador del Estado debe tener un tiempo definido, vulneración del debido proceso, se asume que cuando es indefinido amplia el poder coercitivo.

En síntesis, se determinó que lo mencionado por el entrevistado 2 afectaría a la seguridad jurídica.

\section{Entrevistado 3}

Indicó que no, ya que, la corte de DDHH y la comisión que van de la mano, generan estándares para la aplicación de los derechos humanos, y estos estándares, tienen que ser analizados cada uno en su coyuntura. Por lo tanto, la corrupción va a generar cierta protección al Estado y disminución de esa protección al ciudadano, esto no quiere decir que, el ciudadano este totalmente desprotegido.

De esta manera, si se modifica el estándar de la prescripción, cambiando el plazo, requisitos, participación, calificación del hecho, otros, no se les quitan los derechos a las personas, simplemente se le está dando la posibilidad a las personas a que estén informadas. Por ende, si cometen uno de estos delitos, no se les va a tratar como una persona que haya cometido un delito de robo, si no de otra forma, es por eso que los convenios que se hayan realizado en 1998, 2000 y el 2002 con la ONU, sobre la lucha de la corrupción en el caso del enriquecimiento ilícito, se tienen la inversión de la carga como la prueba. Es así, como no es favorable hacerlos imprescriptibles, pero si se puede modificar ese estándar. 
Con lo mencionado por el entrevistado 3, se analizó que a mayor sanción menor participación en un delito, además, al aplicar políticas penales a partir de la coyuntura social, no existe una visión de administración integral. Si se afecta la continuidad se deben ampliar los plazos, se tiene que utilizar un estándar conforme a los elementos fácticos y la naturaleza de tipo del delito, sobre la corrupción. Si modificamos el estándar de la prescripción, cambiando el plazo, requisitos, participación, calificación del hecho, no es favorable hacerlos imprescriptibles, pero si se puede modificar ese estándar.

De manera conjunta, se presenta el criterio de los expertos mediante una tabla que concurre la argumentación, análisis y síntesis respecto de la imprescriptibilidad en los delitos de corrupción, se presenta la siguiente Tabla 2:

Tabla 2. Criterio y su posición respecto a la imprescriptibilidad de los delitos de corrupción de expertos.

Entrevistado 1

Evidentemente el estado tiene que luchar contra la corrupción, pero para ello se requiere un sistema penal que cumpla con los estándares del debido proceso y una estructura judicial y fiscal que este conformado por funcionarios de carrera, para demostrar su independencia y su criterio legal, concluyendo que este tipo de delitos no deben ser imprescriptibles porque si realmente quieren luchar contra este tipo de delitos, se debe tener un sistema de control y de operadores que sean eficaces, conformado por personas de carrera que deban su cargo a sus méritos

Entrevistado 2 Desde el ámbito jurisdiccional como ex autoridad judicial este tema ha sido una medida adoptada por el poder legislativo y ejecutivo para sancionar y reprimir los actos de corrupción y evidentemente son políticas de estado que no han sido modificadas desde su promulgación empero corresponde revisar el impacto de la norma en cuanto sanción de los delitos de corrupción en base a las estadísticas y estándares de que si ha habido una notable represión a la corrupción o ésta se ha ido incrementando con las autoridades públicas y que como actualmente se puede evidenciar más el segundo punto porque actualmente hay más actos de corrupción por parte de los servidores públicos y crear una norma que responda a la necesidad y la realidad de nuestro estado

Entrevistado 3

Que exista un índice de participación en un hecho delictivo no necesariamente quiere decir que a mayor sanción menor participación en un delito, es decir que los delitos de corrupción sean imprescriptibles no quiere decir que estos delitos van a quedar impunes, ahí se le está quitando la efectividad que tiene que tener el Estado. Un Estado tiene que ser efectivo en sus sistemas para que la persecución de los delitos penales, por eso a razón de quitarle derechos a las personas existirá una disminución de hechos delictivos, por eso se debe aplicar políticas penales a partir de la coyuntura social. Asimismo, el sistema de administración debe tener una visión totalmente integral, cada funcionario está cumpliendo una función y recibiendo un salario mensual, en la medida que el estado le incremente esa carga procesal y afecte la continuidad, se pueden ampliar los plazos.

Lo expresado por el entrevistado 1, se analizó que el sistema penal no cumple con el debido proceso, estructural judicial y fiscal, no conformada por funcionarios de carrera, por lo tanto, no se evidenció la meritocracia. De esta manera, se patentizó la ausencia de un sistema de control y de operadores eficaces. 
Mientras, con el entrevistado 2, se afirmó que las políticas promulgadas no son revisadas, por lo tanto, es necesario revisar el impacto con base estadística, con el incremento de corrupción.

Por último, con lo expuesto por el entrevistado 3 , se analizó que la imprescriptibilidad no justifica la eliminación de delitos de corrupción, quitándole la efectividad del estado en la persecución de delitos al no ser efectiva.

Con los resultados expuestos anteriormente, se determinó la necesidad de elaborar una propuesta para dar una solución al problema de la investigación.

\section{Propuesta ponencia para la presentación de la transgresión de imprescriptibilidad en delitos de corrupción en la legislación boliviana, que contravienen pactos y convenios internacionales}

\section{Presentación}

Se analiza la consecuente necesidad de combatir la corrupción de manera inquisidora, lo que ha llevado al país a reformar el marco jurídico existente, incluido por cierto, la Constitución Política del Estado, a fin de posibilitar la fórmula de la Imprescriptibilidad de los delitos de corrupción sobrepasando los lineamientos de los Pactos y Convenios Internacionales, a partir de ello, se pretende plantear una ponencia que aunara a entes de carácter internacional responsables del cumplimiento de pactos y tratados internacionales, a fin de producir conclusiones tendientes a modificar las normas nacionales.

\section{Objetivo general}

Proponer una ponencia para la presentación de la transgresión de imprescriptibilidad en delitos de corrupción en la legislación boliviana, que contravienen pactos y convenios internacionales.

\section{Fundamentos legales}

La propuesta desemboca en demostrar que la imprescriptibilidad de los delitos de corrupción, plasmados en la Constitución Política del Estado y en la Ley Marcelo Quiroga Santa Cruz Ley $\mathrm{N}^{\circ} 004$, trasgrede los Pactos y Convenios Internacionales, toda vez que la comunidad internacional considera una vulneración de derechos humanos la imprescriptibilidad de los delitos contra la administración pública, en este sentido, dichos pactos y convenios internacionales se encuentran por encima de la norma constitucional, y como consecuencia no es posible la aplicación de esta normativa supra- constitucional dado el contexto legal estaría violando, el derecho de defensa formal y material mismos que se encuentran plenamente garantizados en el artículo 132 de la Carta Suprema, a estas garantías se aúnan derechos y principios que fundamentan el principio constitucional del debido proceso. A pesar de que se hallan reconocidos y garantizados estos 
derechos y principios, la imprescriptibilidad dentro de los delitos contra la administración pública es contraria a estos preceptos, observándose una vulneración en cuanto al principio y derecho de igualdad.

\section{Contenido}

La proposición científica encuentra fundamento y asidero verificable en los datos producidos y recabados a través de los instrumentos utilizados. El punto central del trabajo de investigación, es la presentación de una ponencia que involucre actores vinculados al cumplimiento de pactos y convenios internacionales, escenario en el que se quiere demostrar la transgresión de los referidos pactos y convenios internacionales sobre derechos humanos, respecto a la imprescriptibilidad de los delitos de corrupción plasmados en la Constitución Política del Estado y la Ley Marcelo Quiroga Santa Cruz.

No queda claro, porque si Bolivia en su calidad de país suscriptor de diferentes tratados y pactos internacionales con relación a los DDHH tiene vigente desde el año 2009 una constitución sumamente garantista, entonces porqué el ordenamiento jurídico vigente tiene tantas falencias con relación a este tema. En ese sentido, la aplicación de las reglas de prescripción reguladas en el ordenamiento penal boliviano permite únicamente los delitos de corrupción. Los delitos vinculados a la corrupción cometidos por servidores públicos no se extinguen por el transcurso del tiempo. En tal sentido, cualquier hecho realizado en la actualidad puede ser investigado en el futuro y en cualquier momento sin ningún obstáculo legal, mientras no sea sometida a un examen de constitucionalidad por la vía pertinente (artículo 132 CPE) y sea ésta resuelta por el Tribunal Constitucional Plurinacional, por lo que el simple paso del tiempo, en lugar de generar la persecución del delito pueda devenir la impunidad de los crímenes más descarados cometidos de corrupción que Bolivia aun padece.

Asimismo, el procesamiento de estos crímenes como delitos imprescriptibles va a favor de violar el principio de legalidad de la ley penal. En ese sentido, una solución, solo desde la perspectiva de la legislación nacional, sería la aplicación de otro tipo de mecanismos proteccionistas.

\section{Recursos}

\section{Humanos}

Conformación de un equipo de profesionales en derecho con especialidad en derecho constitucional, derecho internacional, derecho penal y derechos humanos, con experiencia laboral en los referidos rubros, que reúnen un perfil académico, humanístico, y reflexivo con capacidad de socializar en un contexto internacional, la posición vulnerada de un funcionario público en el cumplimiento de sus funciones y al Estado, con un aparato administrativo con capacidad de resolver los conflictos económicos resultantes de hechos de corrupción. 


\section{Materiales}

Los recursos materiales involucran la inversión para movilidad, alojamientos materiales didácticos y producción de imprenta. Asimismo, el arriendo de un claustro con capacidades y recursos académicos audiovisuales y de grabación que permitan la documentación del evento.

\section{CONCLUSIONES}

Dando cumplimiento al objetivo general de la investigación se llegó a la conclusión que la Constitución Política del Estado Plurinacional (artículo 112) Ley 004 (artículo 29 bis), transgrede los derechos reconocidos en los pactos y convenios internacionales, respecto de la imprescriptibilidad en delitos de corrupción, demostrado en la violación al principio de legalidad, en razón a lo establecido en el artículo 256 de la Constitución Política del Estado, que establece que los derechos humanos definidos en los Pactos y Tratados Internacionales deben aplicarse de manera preferente por encima de cualquier ley o del texto mismo de la Constitución.

Con respecto a la identificación de la naturaleza de la figura jurídica en los delitos de corrupción incorporada en la legislación boliviana, el desarrollo no establece una fundamentación en virtud a la calificación de qué delitos son considerados graves, generando vicios de constitucionalidad.

Para finalizar, con la propuesta Ponencia para la presentación de la transgresión de imprescriptibilidad en delitos de corrupción en la legislación boliviana, que contravienen pactos y convenios internacionales, se permitirá garantizar el principio de legalidad y el sometimiento de control internacional de cumplimiento de las obligaciones internacionales.

\section{REFERENCIAS}

Asamblea Nacional Constituyente, Constitución de la República Bolivariana de Venezuela. Gaceta Oficial Extraordinaria $N^{\circ} 36860$ de fecha 30 de diciembre de 1999

Asamblea Nacional Constituyente, Constitución de la República del Ecuador, Registro Oficial No. 449, 20 de octubre 2008

Asamblea Legislativa. (2010). Ley 004. La Paz Bolivia: Gaceta Oficial. Nacional, C. (1999)

Calduch, R. (1998). Métodos y técnicas de investigación internacional. Madrid

Castro, S. (2003). Derecho Procesal Penal. Tomo 1. En C. S. Castro, Derecho Procesal Penal Tomo 1 (p. 392)

Freire, L. (1998). Causas de Extinción de la acción penal y de la pena (p. 48). Lima: Grijley

Instituto de Defensa Legal. (2012). Prescripción y Retroactividad de la Acción Penal para los casos de corrupción de funcionarios. Lima
Ley 1970. La Paz - Bolivia: Gaceta Oficial

Naciones Unidas (2000). Convención de las Naciones Unidas Contra la Delincuencia Organizada Transnacional y sus protocolos. Oficina contra la Droga y Delito

Pacto de San José. (1969). San José de Costa Rica

Tribunal Constitucional Plurinacional. (16 de enero de 2007). Tribunal Constitucional Plurinacional. Obtenido de Tribunal Constitucional Plurinacional: https://buscador. tcpbolivia.bo

Villanueva, V. C. (2009). El Nuevo Proceso Penal Peruano. En V. C. Villanueva, El Nuevo Proceso Penal Peruano (p. 129). Lima: Palestra 